\title{
EL DERECHO A LA ALIMENTACIÓN ADECUADA EN CHILE Y SU NECESARIA CONSAGRACIÓN COMO DERECHO FUNDAMENTAL EN LA NUEVA CONSTITUCIÓN CHILENA
}

\section{THE RIGHT TO ADEQUATE FOOD IN CHILE AND ITS NECESSARY INCLUSION AS A FUNDAMENTAL RIGHT IN CHILE'S NEW CONSTITUTION}

María Paz Ahumada Ch.*

Óscar A. Cabrera**

Patricio López-Turconi***

\section{RESUMEN}

En el marco del proceso constituyente en Chile, este artículo aborda los argumentos históricos, fácticos y de derecho internacional de los derechos humanos que justifican la incorporación del derecho a la alimentación adecuada como un derecho autónomo en la nueva Constitución. Luego, el cuerpo de este texto evalúa el impacto de esta nueva garantía constitucional en el derecho privado chileno, con especial énfasis en lo que respecta al derecho a la información veraz y oportuna en las relaciones de consumo de alimentos y bebidas. El texto argumenta que, en última instancia, la consagración constitucional de este derecho permitirá extender las normas vigentes sobre información veraz y adecuada en el consumo de alimentos y bebidas, contribuyendo a una mejor garantía de otros derechos humanos relacionados con la alimentación, tales como el derecho a la salud.

* Abogada, Magíster en Derecho Público y Litigación Constitucional, Universidad Diego Portales. Correo electrónico: mp.ahumada.chacon@gmail.com

** Abogado, LL.M. University of Toronto. Correo electrónico: cabrera@law.georgetown. edu

*** Abogado, Universidad Torcuato Di Tella. Correo electrónico: pl730@georgetown.edu Recepción: 2021-06-01; aceptación: 2021-09-13. 
Palabras Clave: Alimentación adecuada; salud; reforma constitucional; Chile; derecho a la alimentación.

\section{Abstract}

Amid the process of constitutional reform in Chile, this article addresses the historical, factual and international human rights arguments that justify the incorporation of the right to adequate food as an autonomous right in the new Constitution. Subsequently, the body of this text assesses the impact of this new constitutional right on Chilean private law, especially regarding the consumer protection regime and the right to be informed. The text argues that, ultimately, a constitutional right to adequate food will allow to extend the current norms on truthful and adequate information for consumers, contributing to a better guarantee of other human rights intrinsically related to food, such as the right to health.

Keywords: Adequate Food; Health; Constitutional Reform; Chile; Right to Adequate Food.

\section{INTRODUCCIÓN}

En Chile, el debate sobre el acceso a una alimentación adecuada no es nuevo, pero sí es una conversación que hasta ahora había permanecido aislada en el mundo académico. La $C P R$ de 1980 no contiene referencia alguna a la alimentación como derecho y, pese a que han existido algunos proyectos de ley para la incorporación del derecho a alimentación adecuada en la actual Carta Fundamental chilena, los mismos no han conseguido el apoyo necesario para su aprobación ${ }^{1}$.

Sin perjuicio de lo anterior, todas las personas enfrentan de forma cotidiana la problemática del acceso a la alimentación adecuada, ya sea a través de políticas públicas de entrega de alimentación complementaria o recurriendo al mercado para conseguir alimentos. La transversalidad de las cuestiones de alimentación y nutrición hace necesario que las mismas sean reguladas desde el prisma del DIDH, desde el derecho constitucional $\mathrm{y}$, por supuesto, desde el derecho privado.

El derecho a la alimentación adecuada ha tenido un amplio desarrollo en el DIDH. El mismo fue definido por el relator especial sobre el derecho a la alimentación de Naciones Unidas, Jean Ziegler, como:

\footnotetext{
${ }^{1}$ Véase, por ejemplo, Cámara de Diputados de Chile (2019).
} 
"[...] el derecho a tener acceso, de manera regular, permanente y libre, sea directamente, sea mediante compra por dinero, a una alimentación cuantitativa y cualitativamente adecuada y suficiente, que corresponda a las tradiciones culturales de la población a que pertenece el consumidor y garantice una vida síquica y física, individual y colectiva, libre de angustias, satisfactoria y digna" ${ }^{2}$.

Pese al vacío constitucional, este derecho se encuentra receptado en distintos tratados internacionales vinculantes ratificados por el Estado de Chile, incluyendo el PIDESC ${ }^{3}$, la $\mathrm{CDN}^{4}$ y la CDPD 5 .

Como se explicará más adelante, estos instrumentos generan obligaciones internacionales para el Estado chileno que deberán ser reflejadas en la redacción de la próxima Carta Fundamental, en tanto las disposiciones del derecho interno nunca pueden ser invocadas como justificación del incumplimiento de un tratado internacional ${ }^{6}$.

En lo que respecta al derecho constitucional, el contexto de elaboración de una nueva Carta Fundamental, además de la situación sanitaria del país, hacen procedente una reflexión sincera acerca de la importancia de que el nuevo texto constitucional consagre a la alimentación adecuada como un derecho fundamental, autónomo y justiciable. Lo anterior podría ser decisivo para impulsar la ejecución de una política pública nacional que, por un lado, garantice la alimentación adecuada y suficiente y, por el otro, involucre al sector público y a todos los actores del ámbito privado.

A su turno, desde el derecho privado se regula la situación más cotidiana y generalizada asociada a la alimentación, que es la decisión de comprar unos u otros alimentos, ya sea para consumo propio o de terceros. Estas decisiones se ven influenciadas por todas las variables que caracterizan a las relaciones de consumo, y en especial por las asimetrías de información entre quienes participan en la cadena de consumo.

En atención a las consideraciones anteriores, este trabajo busca dilucidar si es necesario que la nueva Constitución reconozca el derecho a la alimentación adecuada tal como ha sido desarrollado por el DIDH para, en un segundo término, evaluar cuál sería el impacto de esta garantía constitucional en lo que respecta al derecho a la información veraz y oportuna en el contexto de una relación de consumo.

\footnotetext{
${ }^{2}$ Ziegler (2001), p. 9.

${ }^{3}$ PIDESC, art. 11.

${ }^{4} \mathrm{CDN}$, art. 24.

${ }^{5}$ CDPD, arts. 25 y 28.

${ }^{6}$ CVDT, art. 27.
} 
La metodología aquí utilizada consistió en analizar: en primer lugar, el contenido de los catálogos de derechos fundamentales de los distintos textos constitucionales chilenos. Luego, se utilizó el método dogmático para el estudio de las normas del derecho internacional de los derechos humanos referentes al derecho a la alimentación y al derecho a la salud. Asimismo, se aplicó la misma metodología para analizar el art. 3. letra b) de la Ley n. ${ }^{\circ} 19496$, y las principales normas de etiquetado de alimentos vigentes en Chile, con especial énfasis en la Ley n. ${ }^{\circ} 20606$. Por último, se utilizaron datos empíricos obtenidos de diferentes instituciones estatales e internacionales relacionadas con la alimentación y la salud.

Para el análisis de la hipótesis, se procederá de la siguiente forma:

I) Se estudiará el contenido de los catálogos de derechos fundamentales a lo largo de la historia constitucional de Chile;

II) Se analizará en qué medida Chile cumple con los estándares del DIDH en materia de alimentación adecuada y salud;

III) En el ámbito del derecho nacional, se revisará el contenido del derecho a información veraz y oportuna en materia de consumo de alimentos y

IV) Se evaluará de qué forma el derecho a la alimentación adecuada podría contribuir al derecho del consumo, facilitando el acceso a información veraz y oportuna sobre los alimentos en el mercado.

\section{CATÁlogos de DeRechos Fundamentales A LO LARGO DE LA HISTORIA CONSTITUCIONAL DE CHILE}

En este apartado se analizará la forma en que se han delineado los catálogos de derechos fundamentales en cada uno de los textos constitucionales, considerando para ello todos los textos redactados desde 1818, año en que Chile declara la independencia de la corona española, hasta la actualidad. Lo anterior, a fin de esclarecer si, en algún momento de la historia nacional, existió, en los catálogos de derechos fundamentales, alguna referencia significativa relacionada con las cuestiones de alimentación adecuada.

De la lectura del proyecto de Constitución Provisoria para el Estado de Chile de 1818, promulgado durante el gobierno del director supremo Bernardo O'Higgins, puede observase que el mismo señala en su artículo primero, que los hombres gozan del derecho a su seguridad individual, honra, hacienda, libertad e igualdad civil. Sin perjuicio de que se trata de la primera norma del texto, el mismo no profundiza mayormente en el establecimiento de un catálogo de derechos fundamentales, y mucho menos en uno que impusiera obligaciones prestacionales o positivas al 
Estado naciente ${ }^{7}$. El referido texto se centró preeminentemente en el establecimiento de las instituciones que darían sustento al país, lo que puede comprenderse en atención a la juventud de la república. Este modelo se mantuvo en sentido similar en las constituciones políticas de 1822 y 1823 , las que tampoco incluyeron la consagración de una carta de derechos, pero estatuyeron la igualdad, el derecho a ser llamado a los empleos con las condiciones de la ley, la obligación de contribución para los gastos del Estado, las obligaciones para con Dios, el sufragio de los varones bajo determinados supuestos, el acceso a un juicio y el catolicismo como la religión del Estado con exclusión de cualquiera otra ${ }^{8}$. Muy probablemente, el carácter de tales textos constitucionales estuvo motivado por el acervo cultural y político de sus redactores -hombres de la aristocracia nacional, influenciados por la tradición católica- que decidieron poner énfasis en detallar las obligaciones de los habitantes de Chile en asuntos como el comportamiento político, las obligaciones tributarias y la religión que ellos debían profesar.

En 1826 se sancionaron las conocidas Leyes Federales cuyo fin era el establecimiento de un régimen político federal en el país. Sin embargo, este "Proyecto para la Administración de las Provincias" tampoco profundizó la lista de derechos fundamentales reconocidos por los textos constitucionales anteriores.

Más adelante, ya en 1828 se sancionó la primera Carta fundamental que utilizó la denominación de "Constitución Política de la República", la que estuvo vigente hasta el 25 de mayo de 1833. Esta Constitución fue la primera en plantear un catálogo de derechos fundamentales de mayor extensión, destinando su capítulo III a los "Derechos individuales", y estableciendo:

"La Nación asegura a todo hombre, como derechos imprescriptibles e inviolables, la libertad, la seguridad, la propiedad, el derecho de petición, y la facultad de Publicar sus opiniones".

Más tarde, la Constitución de 1833 consagró con algo más de detalle los derechos asegurados constitucionalmente. En particular, el art. 12 del referido texto constitucional estableció que se aseguraba a todos los habitantes los siguientes derechos: la igualdad ante la ley, la admisión de todos los empleos y funciones públicas, la igual repartición de los im-

${ }^{7}$ Véase art. 1. del Proyecto de Constitución Provisoria para el Estado de Chile de 1818.

${ }^{8}$ Arts. 6, 7, 8, 9 y 10 de la Constitución Política del Estado de Chile de 1822; arts. 7, 8, 10 y 136 de la Constitución Política del Estado de Chile de 1823.

${ }^{9}$ Art. 10 de la Constitución Política del Estado de Chile de 1828. 
puestos y contribuciones, la libertad de permanecer en cualquier punto de la república y de trasladarse, la inviolabilidad de todas las propiedades, el derecho de reunirse sin permiso previo y sin armas, el derecho a asociarse sin permiso previo, el derecho a presentar peticiones a todas las autoridades constituidas, por interés general o individual, la libertad de enseñanza y la libertad de publicar sus opiniones por la imprenta sin censura previa ${ }^{10}$. Cabe decir que este texto permaneció vigente hasta 1925, erigiéndose como el texto constitucional que ha permanecido vigente por mayor tiempo en la historia constitucional chilena.

La Constitución de 1925 fue impulsada por un fuerte movimiento social y en plena crisis del sistema parlamentario, clima propicio para que en dicho Texto Fundamental se replanteara el papel del Estado. La Carta Fundamental de 1925 amplió de forma significativa el catálogo de derechos fundamentales, consagrando un "capítulo III" de las "Garantías constitucionales" que iniciaba con un nutrido art. 10, con quince numerales. Dicha norma estableció que la Constitución aseguraba a todos los habitantes de la república: la igualdad ante la ley, la manifestación de todas las creencias o libertad de culto, la libertad de emitir opiniones sin censura previa, el derecho a reunirse sin permiso previo, el derecho de asociarse sin permiso previo, el derecho de presentar peticiones a la autoridad, la libertad de enseñanza, la admisión a todos los empleos y funciones públicas, la igual repartición de los impuestos y contribuciones, el derecho de propiedad en sus diversas especies, la propiedad exclusiva de todo descubrimiento o producción, la inviolabilidad del hogar, la inviolabilidad de la correspondencia, la protección al trabajo, a la industria y a las obras de previsión social y la libertad de permanecer en cualquier punto de la república ${ }^{11}$.

Profundizando en el alcance del referido art. $10 .^{\circ}$ de la $C P R$ de 1925 , es necesario relevar el contenido de sus numerales $7 .^{\circ}$ y $14 .^{\circ}$, los que articularon el primer soporte de prestaciones sociales que, de conformidad a dicho texto, comenzaban a ser resorte del Estado. El numeral 7..$^{\circ}$ stableció de forma expresa: "[...] la educación primaria obligatoria será una atención preferente del Estado" 12 . Por su parte, el numeral $14 .^{\circ}$ instituyó la protección a las obras de previsión social en el siguiente sentido:

"[...] especialmente si se referían a la habitación sana y a las condiciones económicas de la vida, en forma de proporcionar a cada habitante un mínimo de bienestar adecuado a la satisfacción de

${ }^{10}$ Art. 12 de la Constitución Política de la República de Chile de 1833 (cuya numeración cambió con las reformas posteriores, quedando finalmente como art. 10).

${ }^{11}$ Art. 10 de la Constitución Política del Estado de Chile de 1925.

${ }^{12}$ Op. cit., numeral 7. 
sus necesidades personales y a las de su familia. La ley regulará esta organización" ${ }^{13}$.

Más adelante agrega:

"Es deber del estado velar por la salud pública y el bienestar higiénico del país. Deberá destinarse cada año una cantidad de dinero suficiente para mantener un servicio nacional de salubridad"14.

Los dos numerales antes revisados consagraron, por primera vez, una obligación prestacional en cabeza del Estado de Chile para el disfrute de un derecho. El numeral $14 .^{\circ}$ reviste especial relevancia, pues refiere a un mínimo de bienestar adecuado, a la satisfacción de las necesidades personales y las de la familia, pero sin indicar que se entenderá por "necesidades personales" ni hacer referencia a alguna "necesidad personal" especifica. Sin perjuicio de ello, el numeral $14 .^{\circ}$ representa, para algunos autores como Alejandro Silva Bascuñán y María Pía Silva Gallinato ${ }^{15}$, un avance sustancioso, un rechazo al individualismo y una comprensión del Estado como un agente activo, preocupado por facilitar la vida y velar por el interés de toda la población.

Por su parte, la Constitución Política de la República de Chile 1980, vigente al momento de redacción de este artículo, contiene el catálogo de derechos y garantías fundamentales más extenso de la historia constitucional chilena. Dicho catálogo consta de veintiséis numerales que se refieren a la mayoría de las dimensiones de la vida humana, pero casi ninguno de ellos estableció obligaciones estatales de carácter prestacional. A su turno, se observa en el referido catálogo de derechos fundamentales, la desaparición de términos que, utilizados por la $C P R$ de 1925, tales como "mínimo de bienestar", "satisfacción de sus necesidades personales" o "condiciones económicas de vida".

En lo referido a los gastos en materia sanitaria y a la relevancia de la salubridad pública, si la $C P R$ de 1925 había significado un avance, la de 1980 es más bien un retroceso. El texto de 1980 resolvió que el Estado protegerá el libre e igualitario acceso a las acciones de promoción, protección, recuperación y rehabilitación del individuo, pero sin indicar o establecer mínimos en torno las prestaciones respecto de las cuales existiría un acceso igualitario. Posteriormente, se estableció que corresponden al Estado las labores de coordinación y control de acciones relacionadas a la salud, y

${ }^{13}$ Art. 10 numeral $14 .^{\circ}$ de la Constitución Política del Estado de Chile de 1925.

${ }^{14}$ Op. cit.

${ }^{15}$ Silva Bascuñán y Silva Gallinato (2003). 
la garantía de ejecutar las acciones de salud, ya sea que estas se presten a través de instituciones públicas o privadas. Por último, se establece el derecho de elección de cada persona entre un sistema público de salud y uno privado. En los términos regulados en el art. 20 de la $C P R$, el recurso de protección procede, respecto del derecho a la salud, solo en lo relativo a la libertad de elegir el sistema ${ }^{16}$. A pesar de que cierta doctrina entiende que, en virtud de desarrollos jurisprudenciales, el art. 20 de la $C P R$ permite una protección de la dimensión prestacional del derecho a la salud -de forma directa o en conexidad con otras garantías, como el derecho a la vida $^{17}$ - algunas Cortes de Apelaciones del país continúan rechazando recursos de protección relacionados con el derecho a la salud sobre la base de que los mismos no habían "alegado el derecho a elegir el sistema de salud [...], único aspecto de dicha garantía que se encuentra protegido" ${ }^{18}$.

Los antecedentes que influyeron en la elaboración de catálogos de derechos fundamentales más robustos en la historia de las Constituciones chilenas, así como también el contexto social que dio origen al actual proceso de cambio constitucional, son elementos que reafirman la idea de que la nueva Constitución cuente con un catálogo de derechos fundamentales más abarcador que el vigente. En particular, la alimentación adecuada es uno de los DESC que deberá ser protegido de forma más 310 ambiciosa, sobre la base de las razones que se exponen en los próximos acápites.

\section{II. ¿CUMple Chile CON los estándares DEL DERECHO INTERNACIONAL DE LOS DERECHOS HUMANOS?}

\section{Derecho a la alimentación adecuada}

Para dar respuesta esta pregunta, primero es necesario dar cuenta del contenido del derecho a la alimentación adecuada en el DIDH. Ello porque, como fuera explicado, la alimentación adecuada tiene amplia recepción en distintos instrumentos del derecho internacional que obligan al Estado chileno, entre los que se destaca el art. 11 del PIDESC ${ }^{19}$.

La observación general n. ${ }^{\circ} 12$ podrá ser un punto de partida para considerar el contenido de este derecho y las obligaciones estatales que de-

${ }^{16}$ Véase art. 19 numeral 9 y 20 de la Constitución Política de la República de Chile de 1980.

${ }^{17}$ Para un análisis jurisprudencial de la protección del derecho a la salud en conexidad con el derecho a la vida, véase ZúÑIGA (2011), p. 39.

${ }^{18}$ Véase, por ejemplo, J. A. P. S. con Hospital Regional de Coyhaique (2020).

${ }^{19}$ PIDESC, art. 11. 
rivan del mismo. Así pues, este documento establece que el derecho a la alimentación no debe asimilarse a un conjunto de calorías, proteínas y otros elementos nutritivos, sino que:

i) Implica accesibilidad física y económica a alimentos adecuados o medios para obtenerlos;

ii) Comprende la disponibilidad de alimentos en cantidad y calidad suficientes para satisfacer las necesidades alimentarias de los individuos, sin sustancias nocivas e

iii) Implica que los alimentos deben ser aceptables para una cultura determinada ${ }^{20}$.

Por otro lado, el concepto de 'adecuación' también está ligado al concepto de 'sostenibilidad', que exige la accesibilidad de esos alimentos en formas que sean sostenibles y que no dificulten el goce de otros derechos humanos ${ }^{21}$.

Asimismo, la observación general n. ${ }^{\circ} 12$ describe cuáles son las principales obligaciones del Estado que se desprenden de este derecho. La principal obligación es la de realización progresiva. Ello implica la adopción de medidas para lograr de forma rápida y progresiva el pleno ejercicio del derecho a una alimentación adecuada. Siendo un Estado parte del PIDESC, Chile se ha comprometido a adoptar medidas para garantizar que toda persona que se encuentre bajo su jurisdicción tenga acceso al mínimo de alimentos esenciales, suficientes, inocuos y nutritivamente adecuados para protegerla contra el hambre ${ }^{22}$. En efecto, de acuerdo con el Comité DESC:

"El Pacto se viola cuando un Estado no garantiza la satisfacción de, al menos, el nivel mínimo esencial necesario para estar protegido contra el hambre" ${ }^{23}$.

Esto es un deber básico que debería estar reflejado en la redacción constitucional.

Según el Comité DESC, el derecho a la alimentación adecuada también impone las obligaciones legales específicas de respetar, proteger, facilitar y realizar. La obligación de respetar implica que los Estados no adopten medidas que tengan por resultado impedir el acceso a una alimentación adecuada; la de proteger requiere que el Estado adopte medidas

${ }^{20}$ Comité de Derechos Económicos, Sociales y Culturales (1999), párrafos 6, 8 y 11; Jusidman (2014), p. S88 (explicando el contenido de este derecho a partir de un resumen de la observación general n. $\left.{ }^{\circ} 12\right)$.

${ }^{21}$ Comité de Derechos Económicos, Sociales y Culturales (1999), párrafo 8.

${ }^{22}$ Op. cit., párrafo 14 .

${ }^{23}$ Op. cit., párrafo 17. 
para velar porque particulares no priven a las personas de acceso a una alimentación adecuada; la de facilitar significa que el Estado debe iniciar actividades tendientes a fortalecer el acceso y la utilización por parte de la población de los recursos que aseguren su seguridad alimentaria; y la de realizar exige que el Estado provea de forma directa de alimentos o recursos a individuos o grupos que sean incapaces de disfrutar una alimentación adecuada por los medios a su alcance ${ }^{24}$.

En síntesis, y de acuerdo con los estándares del DIDH, estas obligaciones se traducen en:

i) Una garantía de acceso al mínimo de alimentos esenciales suficientes inocuos y nutritivamente adecuados para proteger a la población contra el hambre, pero también para garantizar el goce de otros derechos, tales como la salud. Ello requiere que el Estado realice esfuerzos para asegurar el acceso de aquellos que -por circunstancias sociales, políticas, medioambientales, o económicas- se encuentren en riesgo o situación de inseguridad alimentaria.

ii) Una garantía de justiciabilidad. Los titulares del derecho a la alimentación adecuada deben poder reivindicar las violaciones a este derecho a través de una vía expedita, no onerosa, conducente a que sean oídos por un tribunal judicial o administrativo. Ello requiere, además, reconocer a estos tribunales como garantes de la alimentación adecuada.

iii) Un deber de desarrollar iniciativas en materia de educación y difusión de información relativas a la alimentación y nutrición, que permitan comprender a la alimentación adecuada como un fenómeno de relevancia pública. Tal como lo ha establecido el relator especial sobre el derecho a la salud, este derecho también hace necesario que los Estados tomen medidas para proporcionar información precisa, disponible, comprensible y transparente sobre los alimentos, que permita a los consumidores tomar decisiones informadas hacia dietas saludables ${ }^{25}$. Como se mencionará en la próxima sección, ello tiene una estrecha relación con el derecho privado chileno.

iv) Un deber de regulación y fiscalización de los actores involucrados en el acceso a la alimentación adecuada. Ello incluye a la industria de alimentos y bebidas. El Estado no solo debe ser capaz de proveer los mínimos necesarios, sino que, también, debe regular a los actores privados vinculados con el suministro de alimentos, a fin

${ }^{24}$ Comité de Derechos Económicos, Sociales y Culturales (1999), párrafo 15; Véase también Jusidman (2014), p. S89.

${ }^{25}$ Pūras (2020). 
de que cumplan con los criterios de adecuación y sostenibilidad tal como han sido detallados por el Comité DESC.

Ahora bien, un simple análisis del marco constitucional actual da cuenta de que Chile no está en afinidad con las obligaciones internacionales del Estado en materia de alimentación adecuada. En este punto, cabe recordar que el actual art. 19 de la $C P R$ de 1980 no hace referencia alguna a la alimentación, y mucho menos a la alimentación adecuada. De hecho, el término 'alimentación' no está mencionado en ninguna parte del texto constitucional. La actual carta de derechos fundamentales chilena otorga preferencia a los derechos que implican una obligación negativa o de abstención por parte del Estado (i.e., el Estado no puede atentar contra la vida o la integridad personal, entre otras limitaciones) y a las libertades individuales (i.e., la posibilidad de elegir su sistema de salud, el establecimiento educacional al que asistan sus hijos, etc.). Por el contrario, el texto de la CPR de 1980 no contiene, y en muy pocos casos asegura, accesos mínimos relacionados con derechos prestacionales, como la alimentación y la salud ${ }^{26}$.

Estos datos desalentadores exigen repensar el papel del Estado en la realización del derecho a la alimentación saludable en particular. Al momento de redacción de este artículo, el derecho constitucional chileno no ha incorporado los estándares del derecho internacional de los derechos humanos en la materia. Sin embargo, y en virtud del PIDESC, Chile está obligado a tomar medidas y a avanzar de forma progresiva para lograr la efectividad del derecho a la alimentación ${ }^{27}$. Un primer paso en este sentido es, entonces, consagrar a la alimentación adecuada como un derecho constitucional, autónomo, justiciable e indivisible del resto de los derechos humanos. Un reconocimiento normativo de este tipo no solo permitirá adecuar el orden constitucional chileno a los estándares del $\mathrm{DIDH}$, sino que, también, ayudará a incorporar el concepto de "alimentación adecuada" -tal como ha sido interpretado por el Comité DESC-en el derecho privado chileno. En particular, la próxima sección detallará cómo un derecho constitucional a la alimentación adecuada resultará en importantes avances normativos en el derecho del consumo en Chile.

${ }^{26}$ Compárese con Figueroa (2013), p. 288 que se refiere a la teoría según la cual la Constitución de Chile sí protege el derecho a la salud en su dimensión prestacional, a pesar de no estar de forma expresa mencionado en el texto, en tanto "no existe fundamento para apoyar la tesis de que existe una distinción relevante entre 'derecho a la salud' y 'derecho a la protección de la salud'”.

${ }^{27}$ Henríquez (2008).Véase el análisis ofrecido por Miriam Henríquez Viñas quien, a través de un análisis de casos, sostiene que -desde 2005- los tribunales nacionales han reconocido la preeminencia de la aplicación de los tratados de derechos humanos ante un conflicto con la legislación interna. 


\section{Derecho a salud y su estrecha relación con la alimentación adecuada}

La alimentación adecuada está vinculada con el derecho a la salud, toda vez que es el principal factor socioeconómico que puede influir de forma directa en el disfrute del más alto nivel posible de salud física y mental. En efecto, el Comité DESC ha entendido que tanto la nutrición adecuada como el suministro adecuado de alimentos sanos deben entenderse abarcados por el concepto de "derecho a la salud", en tanto se encuentran entre aquellos factores que permiten que las personas puedan llevar adelante una vida sana. En particular, este Comité ha resaltado que el derecho a la salud está estrechamente vinculado con, y depende de, el derecho a la alimentación ${ }^{28}$.

El papel de la alimentación como factor determinante de la salud queda de resalto cuando se analiza la magnitud y el impacto de las ENT asociadas a la mala alimentación, las que son de alta prevalencia en Chile. En efecto, de acuerdo con la Política Nacional de Alimentación y Nutrición de Chile de 2017, una de cada siete muertes se debe a la hipertensión, una de cada ocho al consumo excesivo de sal, una de cada diez muertes se debe al consumo de alcohol, mientras que una de cada once se debe al sobrepeso y a la obesidad ${ }^{29}$.

Los datos antes indicados están vinculados con el aumento de las dietas malsanas en el país, hecho que queda de manifiesto al observar las cifras de la última Encuesta Nacional de Salud. De acuerdo con este estudio, solo el $15 \%$ de la población chilena consume al menos las cinco porciones de frutas y verduras por día que recomiendan la Organización Mundial de la Salud y la Organización Panamericana de la Salud. Además, cerca del $13 \%$ de las personas que tienen un nivel de formación de entre ocho a doce años consume las referidas cinco porciones, cifra que se eleva a un 20,1\% para aquellas personas que han cursado más de doce años de estudios ${ }^{30}$.

\footnotetext{
${ }^{28}$ Comité de Derechos Económicos, Sociales y Culturales (2000), párrafos 4, 11 y 15.

${ }^{29}$ Ministerio de Salud del Gobierno de Chile (2017a); Ministerio de Salud del Gobierno de Chile (2017b).

${ }^{30}$ Cabe agregar que la Encuesta Nacional de Consumo Alimentario reveló, entre otras cosas, que las personas de niveles socioeconómicos más bajos y del área rural presentan un mayor consumo de alimentos con alto contenido de nutrientes críticos y energía, bajísimo consumo de pescado, menor consumo de alimentos con nutrientes protectores. Además, la ingesta excesiva de energía es muy significativa en las zonas extremas del país, y va en aumento en tanto disminuye el nivel socioeconómico. Véase, EQUIPO DE Trabajo Encuesta Nacional de Consumo Alimentario, Escuela de Salud Pública, Departamento de Nutrición, Escuela de Nutrición, Centro de Microdatos, Asesoría Técnica Internacional de la Universidad de Chile (2016).
} 
Cabe destacar que, de acuerdo con el Comité DESC, el derecho a la salud no solo abarca la atención de salud oportuna y apropiada, también comprende los principales factores determinantes de la salud, como el suministro adecuado de alimentos sanos y una nutrición adecuada. Ello quiere decir que existen dos dimensiones del derecho a la salud integral: una dimensión prestacional, que comprende los servicios paliativos, de curación y de rehabilitación, y una dimensión preventiva, que abarca la prevención oportuna y apropiada y la promoción de la salud. Ambas dimensiones se encuentran receptadas en el párrafo 12.2.(c) del PIDESC, que indica que -para dar plena efectividad al derecho a la salud- los Estados deberán tomar medidas para "la prevención y el tratamiento de las enfermedades epidémicas, endémicas, profesionales y de otra índole [...]"31.

La dimensión preventiva del derecho a la salud cobra especial relevancia en materia de alimentación, ya que garantizar el acceso a una alimentación nutritivamente adecuada constituye una herramienta efectiva para, por un lado, prevenir el desarrollo y aliviar la carga de la epidemia de las enfermedades no transmisibles vinculadas a la alimentación y, por el otro, garantizar entornos alimentarios saludables. Los Estados pueden dar cumplimiento a su deber de prevenir las ENT asociadas a la mala alimentación a través de la regulación de las actividades de particulares, grupos o empresas relacionados con el suministro de alimentos adecuados. De hecho, el acceso a la información sobre el contenido nutricional de los productos forma parte del componente de accesibilidad del derecho a la salud, y constituye uno de sus factores determinantes. De acuerdo con el relator especial sobre el derecho de toda persona al disfrute del más alto nivel posible de salud física y mental, los Estados ejecutan su obligación de proteger el derecho a la salud cuando, entre otras cosas, reglamentan las actividades de las industrias de alimentos y bebidas para garantizar que transmitan información exacta sobre sus productos ${ }^{32}$.

En el próximo apartado se analizará de qué forma un derecho constitucional a la alimentación adecuada provocará cambios normativos en el derecho privado chileno que, a su vez, facilitarán el cumplimiento de las obligaciones estatales que se derivan de la dimensión preventiva del derecho a la salud.

${ }^{31}$ PIDESC, art. 12.2.(c) (énfasis agregado); Comité de Derechos Económicos, Sociales y Culturales (2000), párrafo 11; véase, además, Sarmiento \& Walker abogados ET AL. (2020), p. 5.

32 Pūras (2020); Grover (2014), párrafo 13. 


\section{EL IMPACTO DEL DERECHO A LA ALIMENTACIÓN ADECUADA EN LAS RELACIONES DE CONSUMO DE ALIMENTOS Y BEBIDAS}

Como quedara de resalto en las secciones anteriores, el cumplimiento del derecho a la alimentación adecuada -y de otros derechos como la saluddepende de que las personas puedan acceder a información exacta sobre los alimentos que consumen o adquieren en el mercado. En ese sentido, esta sección revisará el contenido del derecho a la información veraz y oportuna en materia de consumo de alimentos, para dilucidar la relación entre esta dimensión del derecho privado y la eventual consagración del derecho a la alimentación adecuada en la próxima Constitución de Chile. Este análisis intentará demostrar que, en definitiva, una garantía constitucional a la alimentación adecuada podría facilitar el acceso a la información veraz y oportuna en las relaciones de consumo asociadas a alimentos.

\section{Recepción normativa del derecho a la información del consumidor en Chile}

A diferencia de otros países de la región, Chile ${ }^{33}$ no cuenta con un reconocimiento constitucional de los derechos del consumidor. En efecto, la protección a este grupo se consagra en normas de rango legal, siendo su norma basal la LPDC de 1997. Como lo señala su art. 1. ${ }^{\circ}$, esta norma tiene por objetivo regular las relaciones entre proveedores y consumidores, establecer las infracciones en perjuicio del consumidor y señalar el procedimiento aplicable en estas materias ${ }^{34}$.

La desigualdad manifiesta que se da en las relaciones jurídicas que se originan en las prácticas de consumo -que es propia de las nuevas y masivas formas de contratación- desvanece la imagen clásica del contrato en que los contratantes son partes negociadoras en igualdad de condiciones, y las reemplaza por estipulantes y aceptantes. Los primeros son los representantes de las grandes empresas, y los segundos, no son otra cosa que los consumidores, que pueden aceptar o no aquello que les es ofrecido ${ }^{35}$ o -en el mejor de los casos- escoger entre los distintos proveedores que ofrecen el bien o servicio de que se trate ${ }^{36}$. Según la doctrina, la asimetría

${ }^{33}$ IsLER (2019), pp. 180-181 identificando dos técnicas que el poder constituyente podría utilizar para proteger a los consumidores: incorporar nuevas garantías en los catálogos de derechos fundamentales o reconocer al grupo tutelado a propósito del sistema económico.

${ }^{34}$ Art. $1 .^{\circ}$ de la Ley n. ${ }^{\circ} 19496$.

${ }^{35}$ Aimone (2013), p. 5.

${ }^{36}$ Momberg (2006), p. 598. 
entre proveedores y consumidores se manifiesta con especial énfasis en las diferencias de información que cada uno de los contratantes maneja ${ }^{37}$.

Dada la diferencia en la aptitud negociadora de las partes, la LPDC en su art. 3, recepta una serie de derechos-deberes de los consumidores, entre los que se destaca el derecho a la información veraz y oportuna sobre los bienes y servicios ofrecidos, su precio, condiciones de contratación y otras características relevantes de los mismos ${ }^{38}$.

Según la doctrina, este derecho-deber es una de las principales técnicas de protección en favor de los consumidores, en tanto permite que los mismos puedan ser más libres en la elección de bienes o servicios ${ }^{39}$. Cabe agregar que sobre la prerrogativa del derecho a la información veraz y oportuna, descansa la mayoría de los otros derechos de los que se encuentran premunidos los consumidores, pues ella permite una elección reflexiva, propende a la educación de los consumidores, contribuye a disminuir riesgos y posibilita un consumo más seguro, entre otros derechos ${ }^{40,41}$.

Del contenido del art. $3^{\circ}$ letra b) de la LPDC, se desprende que la información que el proveedor debe ofrecer al consumidor debe resguardar la verdad, prescindiendo de mentiras o engaños, no generando expectativas falsas, erradas o inidóneas sobre el bien o servicio de que se trate. Además, la información debe ser proporcionada cuando el consumidor la requiera y contener una descripción del bien o servicio y de todas las cualidades esenciales del mismo. Por último, el proveedor está obligado -en todo momento- a informar sobre el precio, las condiciones de la contratación o los términos y condiciones y otras características relevantes, si correspondiera ${ }^{42,43}$.

Cabe resaltar que el contenido exacto de la información que deberá ser entregada al consumidor también dependerá de la naturaleza del negocio de que se trate $y$, desde luego, a otras normas legales que ayuden a dotar de contenido el derecho consagrado en el art. 3 letra b) de la

${ }^{37}$ Momberg (2006), pp. 593-594; Fernández (2003), p. 4; De La Maza (2010), pp. 22-23.

${ }^{38}$ Cabe tener presente que la relevancia del derecho-deber de información se refuerza con lo consagrado en el artículo $4^{\circ}$ de la Ley n. ${ }^{\circ} 19496$, que establece la irrenunciabilidad de los derechos consagrados en el referido cuerpo normativo.

${ }^{39}$ De La Maza (2013), p. 24.

${ }^{40}$ ISLER (2019), p. 207.

${ }^{41}$ EsPada (2013), p. 135.

${ }^{42}$ Barrientos (2019), pp. 38-39.

${ }^{43}$ Fernández (2020), p. 806. Pese a que escapa al propósito de este trabajo el ahondar en la estrecha ligazón entre la publicidad y los deberes generales de información, es importante tener presente que también aquella información entregada a través de tácticas y estrategias publicitarias debe regirse las exigencias que se derivan del art. $3^{\circ}$ letra b) de la Ley n. 19496. 
$\mathrm{LPDC}^{44}$. En ese sentido, la información en las relaciones de consumo de alimentos y bebidas también quedarán regidas por diversas normas de carácter reglamentario, las que serán diferentes según el tipo de producto de que se trate ${ }^{45}$.

El derecho a la información es muy relevante en el ámbito del consumo de alimentos y bebidas dado que -en estos casos- la asimetría entre consumidores y proveedores es bastante radical. En efecto, las características, componentes u origen de los alimentos en general, y de los productos procesados o manufacturados en particular, suelen ser imposibles de descifrar por el consumidor promedio. En la práctica, en materia de consumo de productos alimenticios, las personas dependen casi en forma exclusiva de la información que les revele el proveedor: sin ella, un consumidor solo podría estar seguro de las particularidades de cada alimento luego de un minucioso análisis de laboratorio, lo que se aleja por mucho del deber de informarse que compete a un consumidor diligente, pero a fin de cuentas común ${ }^{46}$.

En materia de alimentos y bebidas, la principal forma de entrega de información es el etiquetado. Ello se desprende del art. 29 de la LPDC, que establece:

"El que estando obligado a rotular los bienes o servicios que produzca, expenda o preste, no lo hiciere, o faltare a la verdad en la rotulación, la ocultare o alterare, será sancionado con multa de hasta 300 unidades tributarias mensuales",

en relación con la norma del artículo 50 del mismo cuerpo normativo.

Ahora bien, en materia del contenido del etiquetado de alimentos, este se encuentra principalmente regido por la Ley n. ${ }^{\circ} 20606$, sobre Composición Nutricional de Los Alimentos y su Publicidad ${ }^{47}$. La historia legislativa

${ }^{44}$ De La MaZa (2013), p. 27; Barrientos (2019), p. 35.

${ }^{45}$ Fernández (2003), pp. 51-52.

${ }^{46}$ BARrientos (2013), p. 102. El autor destaca la causa rol n. ${ }^{\circ} 9200-2004-2$, del Juzgado de Policía Local de San Miguel, originado por la mala rotulación de un alimento por parte de la empresa Winter S.A. en que la misma alega: "[...] la singularización del número de lote, bastará para satisfacer la normativa legal vigente, toda vez que, cualquier persona podría comprobar en los registros de la empresa la fecha de elaboración de los productos". Para el tribunal: "Tal postura importaría una imposición a los consumidores en orden a averiguar por sus propios medios, ciertos antecedentes de los productos que adquieren en este caso, la fecha de elaboración [...] tal situación se contrapone al espíritu de la ley sobre protección a los derechos del consumidor, toda vez que el deber de informar pesa sobre los proveedores de bienes y servicios [...]”.

${ }^{47}$ Téngase presente otras normas que establecen deberes de rotulación e información, tales como los arts. 10 y 11 del decreto n. ${ }^{\circ} 239$; art. 35 de la Ley n. ${ }^{\circ} 18455$ y art. 1 . de la Ley $n^{\circ} 21363$. 
de esta norma toma, como punto de partida, la alta prevalencia de las ENT en Chile -a la que se hizo referencia en las secciones anteriores- y responde a la dimensión preventiva del derecho a la salud.

En efecto, la nueva Ley n. ${ }^{\circ} 20606$ constituyó un cambio de rumbo en el ordenamiento nacional, toda vez que dicha norma no tiende solo a proteger al consumidor frente a engaños o faltas del proveedor, sino que procura también la protección del consumidor frente a prácticas masivas, tales como: la fabricación, envase, conservación, rotulado y tiempo ${ }^{48}$.

A mayor abundamiento, la referida Ley n. ${ }^{\circ} 20606$ busca realizar el derecho a la información en el consumo de alimentos y bebidas lo que, a su vez, facilita que las personas puedan adoptar decisiones saludables. En ese sentido, se trata de una clara política pública en la que el derecho público -o las obligaciones internacionales del Estado en materia de salud y alimentación adecuada- impactan en el derecho privado chileno.

Para dar cumplimiento a lo anterior, el art. 2. ${ }^{\circ}$ de la Ley n. ${ }^{\circ} 20606$ establece la obligación de los fabricantes, productores, distribuidores e importadores de alimentos, en torno a informar en sus envases o etiquetas los ingredientes que contienen, sus aditivos y demás información nutricional $^{49}$. Asimismo, la referida disposición establece que corresponderá al Reglamento Sanitario de Alimentos determinar la forma, tamaño, colores, proporción características y contenido de las etiquetas y rótulos nutricionales de los alimentos. De igual modo, dispone, en su art. 120, que todos los productos alimenticios que se almacenen, transporten o expendan envasados deberán llevar los sellos negros octagonales que indican "alto en..." para expresar el componente crítico de grasas saturadas, sodio, azucares o calorías, además de otras especificaciones en torno a los descriptores de los productos ${ }^{50}$.

El etiquetado frontal de advertencia adoptado en Chile mediante la Ley n. ${ }^{\circ} 20606$, ha sido reconocido como una política de salud pública efectiva que, además, es idónea para cumplir con las obligaciones internacionales que se desprenden de los derechos a la salud y a la alimentación adecuada. Más aún, esta norma es todavía uno de los modelos pioneros en el mundo y uno de los ejemplos que muchos países buscan imitar ${ }^{51}$.

Sin embargo, la mencionada Ley n. 20606 y el Reglamento Sanitario de Alimentos solo comprenden a los productos envasados, dejando fuera importantes mercados, como son: los alimentos que se compran a granel, los alimentos preparados a los que se accede a través de los servicios de

\footnotetext{
${ }^{48}$ Aimone (2013), p. 79.

${ }^{49}$ Art. 2 de la Ley n. ${ }^{\circ} 20606$.

${ }^{50}$ Art. 120 del decreto supremo n. ${ }^{\circ} 977$.

${ }^{51}$ Sarmiento \& Walker abogados et al. (2020), p. 78.
} 
envío a domicilio o take away y los alimentos consumidos en restaurantes o comercios de elaboración y expendio de alimentos.

Lo anterior es preocupante, pues implica que -frente a los supuestos indicados- el consumidor es ciego, y el espíritu de corrección que movía al legislador, a fin de cautelar los derechos de los consumidores, a través de la consagración de los deberes generales de información, se encuentra ausente.

Por otro lado, de la lectura del art. $3 .^{\circ}$ de la LPDC, se desprende que el derecho del consumo en Chile garantiza el derecho a la información a todos los consumidores, sin plantear distinción alguna, no observándose buenas razones para mantener la exclusión de entrega de información de los alimentos en las situaciones descritas precedentemente. Como ya se revisó, las obligaciones internacionales que se desprenden del derecho a la alimentación adecuada y a la salud siguen siendo vinculantes aun en los casos en los que el consumidor adquiere alimentos no envasados. La necesidad de revertir la laguna normativa se hace aún más visible cuando se considera que el proveedor de los productos no envasados también es, muchas veces, una empresa de gran tamaño o una compañía internacional que se posiciona en el mercado a través de franquicias y que elabora sus productos con materias procesadas.

\section{Consagración constitucional del derecho a la alimentación como garantía del derecho a la información veraz y oportuna en el consumo de alimentos y bebidas}

Las particularidades recién apuntadas permiten volver a lo que se ha consignado al inicio: la necesidad de incluir el derecho a la alimentación adecuada en el nuevo texto constitucional, que se encuentre en línea con los estándares del DIDH. Ello implicará reconocer que todos los habitantes de Chile tienen derecho a acceder a alimentos que permitan una nutrición adecuada y apta para la preservación de la salud ${ }^{52}$.

Para reiterar, el concepto de 'adecuación' contenido en el art. 11 del PIDESC incluye el valor nutricional de los productos alimenticios ${ }^{53}$. El derecho a la alimentación adecuada se traduce en un derecho a la calidad nutricional, y no solo el derecho a un mínimo de calorías ${ }^{54}$. En esa línea, aquellos productos -envasados o no-con exceso de nutrientes $\operatorname{críticos}^{55}$, con

${ }^{52}$ Caso Comunidades Indígenas Miembros de la Asociación Lhaka Honhat (Nuestra Tierra) vs. Argentina (2020), párrafos 216 y 220.

${ }^{53}$ Elver (2016), párrafo 74.

${ }^{54}$ Op. cit., párrafo 60 (citando el proyecto de Convenio Marco de Salud Global).

${ }_{55}$ Azúcares, grasas y sodio. 
alto valor calórico y bajo o nulo valor nutricional no satisfarán el derecho a la alimentación adecuada a los fines de lo dispuesto en el art. 11 del PIDEC ${ }^{56}$.

Los derechos a la alimentación y a la salud obligan a Chile a adoptar medidas destinadas a evitar el consumo excesivo y no equilibrado de estos alimentos. En virtud de su obligación de proteger estos derechos, el Estado de Chile tiene el deber de regular a los actores privados para velar porque estos no introduzcan alimentos que interfieran con el acceso a la nutrición cualitativamente adecuada y al goce del más alto nivel de salud, aun cuando estos actores no presenten sus productos de forma envasada. De acuerdo con la relatora especial sobre el derecho a la alimentación, las iniciativas relativas al etiquetado son medidas de protección correctas y adecuadas para regular la industria.

Así, y en vista del principio de supremacía constitucional ${ }^{57}$, la inclusión de la alimentación adecuada en la Constitución permitirá dar cumplimiento a estos deberes. En efecto, la recepción constitucional será una justificación normativa para la extensión de las disposiciones que buscan informar a los consumidores de que determinados productos son perjudiciales para su bienestar nutricional -tales como las reglas de etiquetado frontal- a todos los mercados que han quedado fuera de la regulación vigente en Chile.

En concreto la injerencia del derecho constitucional a la alimentación adecuada sobre el derecho privado se manifestaría de la siguiente forma:

a) Eficacia directa, que significa que los individuos podrán reclamar la protección del derecho constitucional a la alimentación cualitativamente adecuada con la mera invocación de esa norma, a pesar de que el régimen del consumo no reconozca un derecho a la alimentación con esas características.

b) Poder derogatorio, que implica que un derecho constitucional a la alimentación derogará cualquier norma del régimen del consumo que sea contraria al contenido y naturaleza de este derecho.

c) Poder para invalidar, que conlleva a que los tribunales deberán abstenerse de realizar cualquier aplicación del régimen del consumo a un caso en concreto que contradiga el derecho a la alimentación. Este efecto se relaciona con el poder derogatorio, ya mencionado.

d) Eficacia interpretativa, que denota que los tribunales tendrán el mandato de interpretar las reglas del derecho privado a la luz de los

${ }^{56}$ Caso Comunidades Indígenas Miembros de la Asociación Lhaka Honhat (Nuestra Tierra) vs. Argentina (2020), párrafo 220; Comité de Derechos Económicos, Sociales y Culturales (1999), párrafo 7.

${ }^{57}$ IsLer (2019), p. 179 que expresa que los preceptos de la Constitución son aplicables de manera directa a la relación de consumo. 
estándares internacionales sobre alimentación adecuada, desarrollados en la primera parte de este texto ${ }^{58}$.

En el caso de los productos no saludables, la "eficacia directa" del derecho constitucional sobre el derecho privado permitirá reclamar el cumplimiento del derecho a una alimentación y nutrición adecuadas en todo expendio de alimentos, por lo que la información sobre la calidad nutricional de los productos deberá entregarse en cualquier relación de consumo de alimentos y bebidas.

En la práctica, ello implicará que los vendedores de alimentos a granel, quienes ofrezcan alimentos y bebidas no envasadas a través de envío a domicilio o take away, y quienes vendan alimentos en restaurantes o comercios, también quedarán alcanzados por el deber de información. Una primera forma de materializar este deber podría ser la extensión, sin más, de las normas de etiquetado vigente (i.e., el octógono negro) a estos productos. Sin embargo, ello podría resultar poco adecuado -o, incluso, irrealizable- en muchos casos, en virtud de la naturaleza de los productos y de las prácticas de comercialización. Por ejemplo, quien maneja un restaurante puede no conocer, con exactitud, cuál es la cantidad exacta de sodio, azúcares o grasas saturadas que contienen sus productos.

322 Por ese motivo, la "eficacia directa" de un derecho constitucional a la alimentación adecuada requerirá un trabajo de adecuación normativa de la Ley n. ${ }^{\circ} 20606$, porque las normas vigentes sobre etiquetado de productos envasados no pueden ser extrapoladas, de forma directa, a los productos no envasados ${ }^{59}$.

Este trabajo no busca proporcionar el diseño de la política pública más adecuada para este fin: la adecuación normativa puede ser realizada de varias maneras ${ }^{60}$, pero la definición del método más apropiado corresponderá al trabajo que recaiga en el Poder Legislativo de Chile. Por el contrario, este artículo busca apuntar que la consagración de un derecho a la alimentación adecuada en la próxima Constitución ampliará el alcance

${ }^{58}$ Esta tipología está inspirada en el trabajo hecho por las y los juristas argentinos al analizar el fenómeno de la "constitucionalización" del derecho privado. Véase, por ejemplo, Rivera y Crovi (2016), p. 8.

${ }^{59}$ Como fuera mencionado, el contenido exacto de la información que deberá ser suministrada al consumidor depende de la naturaleza del negocio del que se trate. Por ello, la forma de entrega de información será distinta según se trate de productos envasados o no envasados.

${ }^{60}$ Por ejemplo, exigiendo que quien maneja un restaurante entregue información aproximada sobre el contenido nutricional de los alimentos en los menús o en cualquier otro método de publicidad. Esta es una práctica que ya se realiza en algunos países. Véase, por ejemplo, FDA (2020). 
de los derechos del consumidor y, en general, tendrá un impacto positivo en las relaciones de consumo de alimentos y bebidas.

Por último, en virtud del principio de "eficacia interpretativa", los tribunales de justicia podrán utilizar el eventual derecho constitucional a la alimentación -y los estándares de DIDH en los que se inspira- para precisar las normas del derecho de consumo. En concreto, será una herramienta para definir qué implica el estándar de información veraz y oportuna en las relaciones de consumo de alimentos y bebidas, armonizando las normas del régimen del consumo con las nuevas garantías constitucionales y los tratados de derechos humanos. Así, el trabajo interpretativo contribuirá, de forma definitiva, a que Chile incorpore de forma progresiva los estándares del derecho internacional de los derechos humanos en la materia.

\section{Conclusiones}

El estudio de la historia constitucional chilena demuestra que ningún texto constitucional ha consagrado, hasta la fecha, un catálogo de derechos económicos, sociales y culturales ambicioso y robusto, ni mucho menos uno en que tuviese cabida el derecho a la alimentación adecuada como derecho autónomo, o conexo a otro derecho fundamental como el derecho a la salud. Sin embargo, el texto constitucional de 1925 intentó articular un primer soporte de prestaciones sociales asociadas a un mínimo de bienestar adecuado a la satisfacción de sus necesidades personales, a la salud pública y al bienestar higiénico del país, lo que podría haber servido de base para la integración de derechos como el que se ha analizado en esta investigación. Sin embargo, el soporte al que se ha hecho referencia fue reversado en el texto vigente.

En contraste a lo anterior, los datos empíricos relevados dan cuenta de que la situación sanitaria en Chile se encuentra desfavorable y severamente afectada por la epidemia de obesidad y de las ENT asociadas a la mala alimentación. Es decir, la realidad sanitaria del país exige pensar, con urgencia, en mecanismos que puedan conducir a la pronta realización de la alimentación saludable para la población. Un primer paso en este sentido es la consagración del derecho constitucional a la alimentación adecuada, que recepte los desarrollos normativos del sistema universal en la materia.

Asimismo, este análisis también permite concluir que la alimentación adecuada está relacionada con los derechos a la salud y a la información, que Chile también se encuentra obligado a respetar, proteger y cumplir. En esa línea, este trabajo también demuestra que -en virtud del principio de supremacía constitucional- una garantía constitucional a la alimen- 
tación tendrá un impacto directo sobre las normas del derecho privado que ya intentan proteger la salud y el acceso a la información de las y los consumidores. Así, este estudio explica que la principal consecuencia será la extensión del estándar de entrega de información al consumidor de alimentos, que se cumple actualmente a través del etiquetado frontal, a todos los actores privados que produzcan o comercialicen alimentos y bebidas, independiente de su forma de presentación al consumidor. Se ha señalado que, en última instancia, esta influencia del derecho constitucional sobre el derecho privado propenderá a un mayor respeto de las obligaciones internacionales que se desprenden del derecho a la salud.

Por último, el estudio de los instrumentos del DIDH también permite concluir que, para dar cumplimiento con sus obligaciones internacionales, un derecho a la alimentación adecuada en la próxima Constitución debería, por lo menos:

i. Asegurar un acceso al mínimo de alimentos esenciales suficientes inocuos y nutritivamente adecuados para proteger a la población contra el hambre;

ii. Permitir la justiciabilidad del derecho a la alimentación, haciendo posible que los titulares puedan reivindicar las violaciones a este derecho a través de una vía expedita, no onerosa, conducente a que sean oídos por un tribunal judicial o administrativo;

iii. Impulsar el desarrollo de iniciativas en materia de educación y difusión, que permitan comprender a la alimentación adecuada como un fenómeno de relevancia pública y

iv. Incorporar el deber de regulación y fiscalización de los actores involucrados en el acceso a la alimentación adecuada. Ello requiere incluir a la industria (productores, fabricantes o distribuidores) a fin de propender al cumplimiento por parte de esta, de los criterios de adecuación y sostenibilidad.

Una redacción constitucional que incorpore los elementos reseñados augura positivos efectos sociales, económicos, políticos y culturales para Chile.

\section{Bibliografía CITADA}

Aimone Gibson, Enrique (2013). Protección de los derechos del consumidor. Santiago: Legal Publishing.

Barrientos Camus, Francisca (2019). Lecciones de derechos del consumidor. Santiago: Thomson Reuters.

Barrientos Zamorano, Marcelo (2013). "Artículo $3^{\circ}$ B) Derecho a información veraz y oportuna. Comentario", en Iñigo De La MAZA Gazmuri y Carlos 
Pizarro Wilson (dirs.), Francisca Barrientos Camus (coord.). La protección de los derechos de los consumidores. Santiago: Legal Publishing.

De la Maza Gazmuri, Iñigo (2010). "El suministro de información como técnica de protección de los consumidores: Los deberes precontractuales de información”. Revista de Derecho, Universidad Católica del Norte, año 17, n. ․ 2. Coquimbo.

De la Maza Gazmuri, Iñigo (2013). "Artículo $1^{\mathrm{o}}$ n. ${ }^{\circ}$ 3. Definición información básica comercial. Comentario”, en Iñigo De La Maza Gazmuri y Carlos PiZARro Wilson (dirs.), Francisca Barrientos Camus (coord.). La protección de los derechos de los consumidores. Santiago: Legal Publishing.

Espada Mallorquín, Susana (2013). "Artículo $3^{\circ} \mathrm{F}$ ) Derecho a la educación para un consumo responsable. Comentario", en Iñigo De La Maza Gazmuri y Carlos Pizarro Wilson (dirs.), Francisca Barrientos Camus (coord.). La protección de los derechos de los consumidores. Santiago: Legal Publishing.

FERnÁNDEZ Fredes, Francisco (2003). Manual de derecho chileno de protección al consumidor. Santiago: Lexis Nexis.

Fernández Ortega, Felipe (2020). "Publicidad legible, comprensible y sin letra chica. Justificación a través del derecho a la información y la integración publicitaria”, en Fabián Elorriaga De Bonis (ed.). Estudios de Derecho Civil XV. XVIIJornadas Nacionales de Derecho Civil. Santiago: Thomson Reuters.

Figueroa GarcíA-Huidobro, Rodolfo (2013). "El derecho a la salud". Estudios Constitucionales, año 11, n. $^{\circ}$ 2. Talca.

Henríquez Viñas, Miriam (2008). "Jerarquía de los tratados de derechos humanos: Análisis jurisprudencial desde el método de casos”. Estudios Constitucionales, año 6, n. $^{\circ}$ 2. Talca.

Isler Soto, Erika (2019). Derecho del consumo. Nociones fundamentales. Valencia: Tirant lo Blanch.

Jusidman-RAPOPORT, Clara (2014). "El derecho a la alimentación como derecho humano”. Salud Pública Mex, vol. 56, n. ${ }^{\circ}$ 1. Santa María Ahuacatitlan.

Momberg, Rodrigo (2006). "El rol de la publicidad en la etapa precontractual de los negocios de consumo y su relación con el Principio de Buena Fe", en Hernán Corral Talcani y María Sara Rodríguez Pinto (coords). Estudios de Derecho Civil II. Código Civil y Principios Generales: Nuevos problemas, nuevas soluciones. IV Jornadas Chilenas de derecho Civil. Santiago: Lexis Nexis.

Rivera y Crovi, Luis Daniel (2016). Derecho civil: parte general. Buenos Aires: Editorial Abeledo-Perrot.

Silva Bascuñán, Alejandro y María Pía Silva Galdinato (2003). "Derechos Humanos en la Constitución de 1925". Ius et Praxis, vol. 9, n. ${ }^{\circ} 1$. Disponible en www. scielo.cl/scielo.php?script=sci_arttext\&pid=S0718-00122003000100013\&lng $=$ en\&nrm=iso\&tlng=es [fecha de consulta: 15 de abril de 2021].

ZÚÑIGA FAJURI, Alejandra (2011). "El derecho a la vida y el derecho a la protección de la salud en la constitución: una regulación necesaria". Estudios Constitucionales, año 9, n. $^{\circ}$ 1. Talca. 


\section{Normas citadas}

Constitución Política del Estado de Chile de 1822. Sancionada y promulgada el 30 de octubre de 1822.

Constitución Política del Estado de Chile de 1823. Promulgada el 29 de diciembre de 1823.

Constitución Política del Estado de Chile de 1828. Promulgada en 8 de agosto de 1828.

Constitución Política de la República de Chile de 1833. Jurada y promulgada el 25 de mayo de 1833, con las reformas efectuadas hasta el 10 de agosto de 1888.

Constitución Política del Estado de Chile de 1925. Promulgada el 18 de septiembre de 1925.

Constitución Política de la República de Chile de 1980. Promulgada el 21 de octubre de 1980.

CVDT. Viena, 23 de mayo de 1969.

CDPD. Nueva York, 30 de marzo de 2007. Diario Oficial de la República de Chile, Santiago 17 de septiembre de 2008.

CDN. Nueva York, 20 de noviembre de 1989. Diario Oficial de la República de Chile, Santiago, 27 de septiembre de 1990.

Decreto Supremo n. ${ }^{\circ}$ 239, del Ministerio de Agricultura. Reglamento General del Sistema Obligatorio de Clasificación de Ganado, Tipificación, Marca

326 y Comercialización de Carne Bovina. Diario Oficial de la República de Chile, Santiago, 26 de octubre de 1993.

Decreto Supremo n. ${ }^{\circ}$ 977, de 1997, del Ministerio de Salud. Reglamento Sanitario de Los Alimentos. Diario Oficial de la República de Chile, Santiago, 13 de mayo de 1997.

Ley n. ${ }^{\circ} 18455$, que Fija Normas Sobre Producción, Elaboración y Comercialización de Alcoholes Etílicos, Bebidas Alcohólicas y Vinagres. Diario Oficial de la República de Chile, Santiago, 11 de noviembre de 1985.

Ley n. ${ }^{\circ}$ 19496, sobre Protección de los Derechos de los Consumidores. Diario Oficial de la República de Chile, Santiago, 7 de marzo de 1997.

Ley n. ${ }^{\circ}$ 19925, sobre Expendio y Consumo de Bebidas Alcohólicas. Diario Oficial de la República de Chile, Santiago, 19 de enero de 2004.

Ley n. ${ }^{\circ} 20606$, sobre Composición Nutricional de los Alimentos y su Publicidad. Diario Oficial de la República de Chile, Santiago, 6 de julio de 2012.

Ley n. ${ }^{\circ} 21363$, que Establece Normas en Materia de Comercialización y Publicidad de Bebidas Alcohólicas. Diario Oficial de la República de Chile, Santiago, 6 de agosto de 2021.

Pacto Internacional de Derechos Económicos, Sociales y Culturales. Nueva York, 16 de diciembre de 1966. Diario Oficial de la República de Chile, Santiago, 27 de mayo de 1989. 


\section{Jurisprudencia citada}

Caso Comunidades Indígenas Miembros de la Asociación Lhaka Honhat (Nuestra Tierra) vs. Argentina (2020): Corte Interamericana de Derechos Humanos, 6 de febrero de 2020. Fondo, Reparaciones y Costas. Serie C n. ${ }^{\circ} 400$.

J. A. P. S. con Hospital Regional de Coyhaique (2020): Corte de Apelaciones de Coyhaique, 19 de noviembre de 2020, CL/JUR/147498/2020.

\section{Documentos de la ONU}

Comité de Derechos Económicos, Sociales y Culturales (1990). "Observación general número 3 relativa a la índole de las obligaciones de los Estados Parte". Documento de la ONU E /1991/23.

Comité de Derechos Económicos, Sociales y Culturales (1999). "Observación general número 12 relativa al derecho a una alimentación adecuada". Documento de la ONU E/C.12/1999/5.

Comité de Derechos Económicos, Sociales y Culturales (2000). “Observación general número 14 relativa al derecho al disfrute del más alto nivel posible de salud". Documento de la ONU E/C.12/2000/4.

Elver, Hilal (2016). "Informe provisional de la relatora especial sobre el derecho a la alimentación”. Documento de la ONU A/71/282.

Grover, Anand (2014). "Los alimentos poco saludables, las enfermedades no transmisibles y el derecho a la salud". Documento de la ONU A/HRC/26/31.

PŨRAS, Dainius (2020). "Statement by the UN Special Rapporteur on the right to health on the adoption of front-of-package warning labelling to tackle NCDs". Disponible en www.ohchr.org/EN/NewsEvents/Pages/DisplayNews. aspx?NewsID=26130\&LangID=E [fecha de consulta: 27 de mayo de 2021].

Ziegler, Jean (2001). "El derecho a la alimentación". Documento de la ONU E/CN.4/2001/53.

\section{Otros documentos citados}

Cámara de Diputados de Chile (2019). "Modifica la Carta Fundamental para asegurar a todas las personas el derecho a la alimentación y a la seguridad alimentaria y nutricional, y amparar su ejercicio con la acción constitucional de protección". Boletín n. ${ }^{\circ}$ 12989-07. Disponible en www.camara.cl/verDoc.aspx?prmTipo=S IAL\&prmID $=50886 \&$ formato $=$ pdf [fecha de consulta: 27 de mayo de 2021].

Equipo de Trabajo Encuesta Nacional de Consumo Alimentario, Escuela de Salud Pública, Departamento de Nutrición, Escuela de Nutrición, Centro de Microdatos, Asesoría Técnica Internacional de la Universidad de CHile (2016). Encuesta nacional de consumo alimentario. Informe final. Disponible en www.minsal.cl/sites/default/files/ENCA-INFORME_FINAL.pdf [fecha de consulta: entre el 20 y el 25 de marzo de 2021]. 
Ministerio de Salud de Chile (2017a). "Política nacional de alimentación y nutrición". Disponible en www.bibliotecaminsal.cl/wp/wp-content/ uploads/2018/01/BVS_POL $\%$ C3\%8DTICA-DE-ALIMENTACI $\%$ C3\%93NY-NUTRICI\%C3\%93N.pdf [fecha de consulta: 8 de abril de 2021].

Ministerio de Salud de Chile (2017b). "Mes del corazón 2017”. Disponible en www.minsal.cl/mes-del-corazon-2017/ [fecha de consulta: 27 de mayo de 2021].

Sarmiento \& Walker abogados ET AL. (2020). Libro recopilatorio del seminario internacional “¿Cómo debe incorporar una nueva constitución el derecho a la salud?. Oportunidades y desafíos del proceso constituyente”. Disponible en www.syw.cl/syw.cl/newsletter/210712_syw_derechosalud.pdf [fecha de consulta: 3 de septiembre de 2021].

FDA (2020). Electronic Code of Federal Regulations. Part 101: Food Labeling. Disponible en www.accessdata.fda.gov/scripts/cdrh/cfdocs/cfcfr/CFRSearch. $\mathrm{cfm} ? \mathrm{fr}=101.11$ [fecha de consulta: 3 de septiembre de 2021].

\section{SigLAS Y ABREVIATURAS}

art. artículo

arts. artículos

328

CDN Convención sobre los Derechos del Niño

CDPD Convención sobre los Derechos de las Personas con Discapacidad

Comité DESC ComitédeDerechosEconómicos,Sociales y Culturales

coord. coordinadora

coords. coordinadores

CPR Constitución Política de la República de Chile

CVDT Convención de Viena sobre el Derecho de los Tratados

DIDH Derecho internacional de los derechos humanos

dirs. directores

ed. editor

ENT Enfermedades No Transmisibles

etc. etcétera

FDA United States Food and Drug Administration

i.e. id est (esto es)

LL.M. Master of Laws 
LPDC Ley n. ${ }^{\circ} 19496$ sobre Protección de los Derechos de los Consumidores

n. ${ }^{\circ}$ número

ONU Organización de las Naciones Unidas

op. cit. opere citato (obra citada)

p. página

PIDESC Pacto Internacional de Derechos Económicos, Sociales y Culturales

pp. páginas

vs. versus

www World Wide Web 